\title{
Production of Inflammatory Cytokines and Nitric Oxide by Human Mast Cells Incubated with Toxoplasma gondii Lysate
}

\author{
Eun-Ah Park¹, Ik-Hwan Han², Jung-Hyun Kim², Soon-Jung Park', Jae-Sook Ryu², Myoung-Hee Ahn²,* \\ 1 Department of Environmental Medical Biology and Institute of Tropical Medicine, Brain Korea 21 PLUS Project for Medical Science, Yonsei \\ University College of Medicine, Seoul 03722, Korea; '2Department of Environmental Biology and Medical Parasitology, Hanyang University College of \\ Medicine, Seoul 04763, Korea
}

\begin{abstract}
The roles of mast cells in allergic diseases and helminth infections are well known. However, the roles of mast cells in T. gondii infection is poorly understood. This study was focused on the production of pro-inflammatory cytokines (TNF-a, IL-4), chemokines (CXCL8, MCP-1) and nitric oxide (NO) by mast cells in response to soluble lysate of $T$. gondii tachyzoites. Production of CXCL8 (IL-8), MCP-1, TNF- $a$ and IL-4 were measured by RT-PCR and ELISA. Western blot were used for detection of CXCR-1 and CXCR2. Our results showed that $T$. gondii lysates triggered mast cells to release CXCL8, MCP-1, TNF-a, IL-4 and to produce NO. This suggests that mast cells play an important role in inflammatory responses to T. gondii.
\end{abstract}

Key words: Toxoplasma gondii, mast cell, cytokine, nitric oxide

Toxoplasma gondii is an obligate intracellular protozoan parasite with a global distribution in humans and other mammals. Although this parasite most often causes subclinical infection, primary infection during pregnancy can induce fetal damage and abortion in both humans and animals. T. gondii is a wellknown inducer of type 1 cytokines, and while these cytokines are required to survive infection, their over-production can be harmful and even lethal $[1,2]$.

Mast cells are abundant in the skin, mucosa of the digestive and respiratory tracts and conjunctiva. These cells provoke IgEmediated allergic responses and are involved in the control of helminth infections of the gastrointestinal tract. They play a key role in innate and adaptive immunity $[3,4]$ and have been shown to induce acute inflammatory reactions in mice in response to intraperitoneal injection of T. gondii [5]. Mast cells also protect the host when $T$. gondii is introduced by the oral route [3]. Mediators produced by activated mast cells may reduce acute inflammation and stimulate parasite clearance in $T$.

- Received 10 December 2018, revised 14 March 2019, accepted 19 March 2019.

*Corresponding author (mhahn@hanyang.ac.kr)

(c) 2019, Korean Society for Parasitology and Tropical Medicine

This is an Open Access article distributed under the terms of the Creative Commons Attribution Non-Commercial License (http://creativecommons.org/licenses/by-nc/4.0) which permits unrestricted non-commercial use, distribution, and reproduction in any medium, provided the original work is properly cited. gondii infections [6]. On the other hand, T. gondii itself inhibits mast cell degranulation by suppressing the mobilization of intracellular $\mathrm{Ca}^{2+}$ by phospholipase C [7]. So, the overall effect of mast cells on T. gondii infections is uncertain. In addition, it is not known whether T. gondii lysates can induce inflammatory responses in the mast cell leukaemia cell line, HMC-1. The aim of this study was to evaluate whether T. gondii lysates induce the activation of HMC-1 cells to release cytokines and nitric oxide.

T. gondii (RH strain) tachyzoites were maintained by intra-peritoneal infection of ICR mice (Osan, Korea). Tachyzoites were harvested from the mice, washed with PBS and centrifuged at low and high speeds ( $500 \mathrm{~g}$ and 3,000 g) for $5 \mathrm{~min}$ to remove peritoneal cells. To prepare T. gondii lysate, the tachyzoites were frozen and thawed 3 times and ultrasonicated at $100 \%$ amplitude, 0.75 cycles, $7-10$ times, until the tachyzoites were completely disrupted. The sonicate was centrifuged at 10,000 g for $1 \mathrm{hr}$, and the supernatant was filtered through a $0.2 \mu \mathrm{m}$ membrane (Millipore, Bedford, Massachusetts, USA). Protein concentrations were determined with the Bradford assay (Bio-Rad, Hercules, California, USA).

Human leukemic mast cells (HMC-1) were grown in IMDM supplemented with $10 \% \mathrm{FBS}$ at $37^{\circ} \mathrm{C}$ in a $5 \%-\mathrm{CO}_{2}$ incubator. To examine cytokine and iNOS mRNA expression, HMC-1 
cells $\left(1.5 \times 10^{6} /\right.$ well $)$ were pretreated with IFN- $\gamma(5 \mu \mathrm{g} / \mathrm{ml}$, ProSpec, East Brunswick New Jersey, USA) for $1 \mathrm{hr}$ and then stimulated with an aliquot of T. gondii lysate $(50 \mu \mathrm{g} / \mathrm{ml})$ or LPS $(10 \mu \mathrm{g} / \mathrm{ml}$, Sigma, St Louis, Missouri, USA). As a positive control, the HMC-1 cells were incubated with PMA $(100 \mathrm{~nm} / \mathrm{ml})$ and A23187 $(10 \mu \mathrm{m} / \mathrm{ml})$. Total RNA was extracted from the cells using Trizol reagent (Invitrogen, Carlsbad, California, USA) and $200 \mu \mathrm{l}$ chloroform (Sigma Aldrich, St. Louis, Missouri, USA). cDNAs were synthesized and reverse-transcribed using RT Premix and PCR Premix (iNtRON Biotechnology, Seongnam, Korea). Primer sequences were as follows; $\beta$-actin (5'-CCA GAG CAA GAG AGG TAT CC-3' and 5'-CTG TGG TGG TGA AGC TGT AG-3'), human IL-8 (5'-GCC AAG AGA ATA TCC GAA CT-3' and 5'-AAA GTG CAA CCA CAT GTC CT-3'), MCP-1 (5'-TCT GTG CCT GCT GCT CAT AG-3' and 5'-GCT GCA GAT TCT TGG GTT GT-3'), IL-4 (5'-CCC TTT CGG CAA AAT CCT CC-3' and 5'-AGG AAT ACA GTG CAG CTT ACC A-3'), TNF- $\alpha$ ( $5^{\prime}$-ACT CTT CTG CCT GCT GCA CTT TGG-3' and 5'-GTT GAC CTT TGT CTG GTA GGA GAC GG-3'), iNOS (5'AGC ATG AGC CCC TTC ATC AAT-3' and 5'-CTG TTT CAA CGA CCT CCG GG-3'), and GAPDH (5'-GTC AGT GGT GGA CCT GAC CT-3' and 5'-AGG GGT CTA CAT GGC AAC TG-3'). PCR conditions were initial DNA denaturation at $94^{\circ} \mathrm{C}$ for 5 min followed by 35 rounds of denaturation at $98^{\circ} \mathrm{C}$ for $15 \mathrm{sec}$, and annealing for $30 \mathrm{~s}$ at $58^{\circ} \mathrm{C}$ for $\beta$-actin, GAPDH \& iNOS, $56^{\circ} \mathrm{C}$ for IL- 8 \& IL- $4,55^{\circ} \mathrm{C}$ for MCP- 1 , and $62^{\circ} \mathrm{C}$ for TNF- $\alpha$, and extension at $72^{\circ} \mathrm{C}$ for $35 \mathrm{sec}$.

To measure IL-8, MCP-1, TNF- $\alpha$ and IL-4 proteins, HMC-1 cells were pretreated with IFN- $\gamma$ followed by exposure to $T$. gondii lysate or LPS for $18 \mathrm{hr}$ or $24 \mathrm{hr}$. Supernatants were collected and stored at $-20^{\circ} \mathrm{C}$ and cytokines were measured by ELISA (BD Biosciences, San Diego, California, USA).

Western blot analysis with monoclonal antibodies was used to detect expression of IL-8 receptor (CXCR1 and CXCR2) on HMC-1 cells which were pretreated with IFN- $\gamma$ for $1 \mathrm{hr}$ followed by T. gondii lysate or LPS. After incubation, the cells were harvested and lysed in PRO-PREP protein extraction solution (iNtRON Biotechnology, Seongnam, Korea). Equal amounts of protein were denatured and separated by SDS-PAGE on $10 \%$ polyacrylamide gels and transferred to Immune-Blot1 PVDF membranes (Bio-Rad, Quarry Bay, HongKong). The membranes were probed with anti-CXCR1 and anti-CXCR2 antibodies (1:1,000; Abcam, Cambridge, UK), or $\beta$-actin polyclonal antibody (1:3,000; Abcam, Cambridge, Massachusetts, USA) overnight at $4^{\circ} \mathrm{C}$ followed by goat anti-rabbit IgG poly- clonal antibody (1:10,000; ADISAB-300-J, Enzo Life Sciences, New York, USA) for $1 \mathrm{hr}$ at room temperature. The blots were visualized using Chemiluminescent Sensitive Plus HRP Microwell and/or Membrane Substrate (SurModics, Minneapolis, Minnesota, USA), and signals were measured with a ChemiDoc1 (Bio-Rad).

For measuring nitric oxide, HMC-1 cells was pretreated with IFN- $\gamma$ followed by T. gondii lysate or LPS for $3 \mathrm{hr}, 6 \mathrm{hr}, 18 \mathrm{hr}$ or $24 \mathrm{hr}$ and supernatants were collected. NO was determined as nitrite using Griess reagent [8].

Statistical analyses were performed with SPSS, version 21 (IBM, Chicago, Illinois, USA). The Mann-Whitney U test was used to compare results, and $P$-values $<0.05$ were considered statistically significant. Data are expressed as means \pm SDs of three independent experiments.

In this experiment, up-regulation of IL-8 mRNA and increased secretion of IL- 8 were observed in the T. gondii-treated HMC-1 cells $6 \mathrm{hr}$ and $18 \mathrm{hr}$ post inoculation (PI), respectively. However the IL-8 levels of HMC-1 cells stimulated with LPS as positive control were significantly higher than those of the of $T$. gondii-stimulated cells. Up-regulations of MCP-1 mRNA and protein were also observed in the HMC-1 cells exposed to $T$. gondii lysate or LPS. Similarly, enhanced TNF- $\alpha$ mRNA expression and increased TNF- $\alpha$ secretion were noted in supernatants of HMC-1 cells treated with $T$. gondii lysate. IL-4 mRNA was also increased by incubation with T. gondii lysate for $24 \mathrm{hr}$, and IL-4 protein increased in the supernatants of treated HMC-1 cells (Fig. 1A, B). To investigate the expression of chemokine receptors for IL-8, CXCR1 and CXCR2 production was analyzed by western blotting after treatment of HMC-1 cells with T. gondii lysate or LPS for $1 \mathrm{hr}$. Both CXCR1 and CXCR2 increased in response to T. gondii lysate (Fig. 1C).

The results in Fig. 2A show that iNOS mRNA increased in HMC-1 cells treated with $T$. gondii lysate for $3 \mathrm{hr}$, and then gradually disappeared. In LPS-treated cells, iNOS mRNA continued to increase between $3 \mathrm{hr}$ and $24 \mathrm{hr}$ of incubation although at a decreasing rate. Maximal NO production in HMC1 cells treated with T. gondii lysate or LPS was observed after 3 hr of stimulation (Fig. 2B).

In T. gondii infections, immune cells including neutrophils, monocytes and macrophages are activated, and also these cells are targets of T. gondii $[9,10]$. T. gondii down-regulates type I immune responses, blocking production of pro-inflammatory cytokine including IFN- $\gamma$ in macrophages and dendritic cells [11]. Mast cells are abundant in the intestinal mucosa and play 
A

$\mathrm{A}_{\mathrm{IL}-8(6 \mathrm{hr})}$

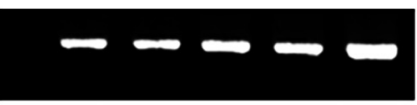

$\beta$-actin

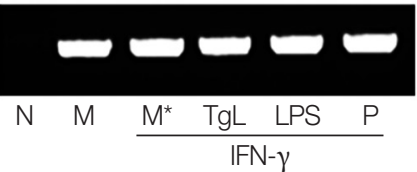

MCP-1 (6 hr)

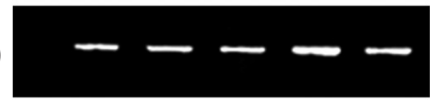

$\beta$-actin
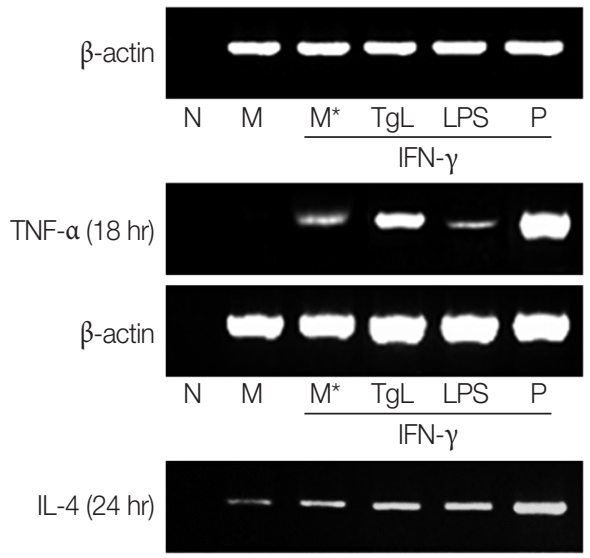

$\beta$-actin

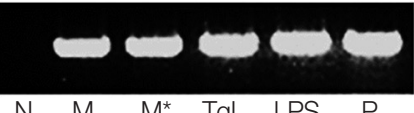

C



B
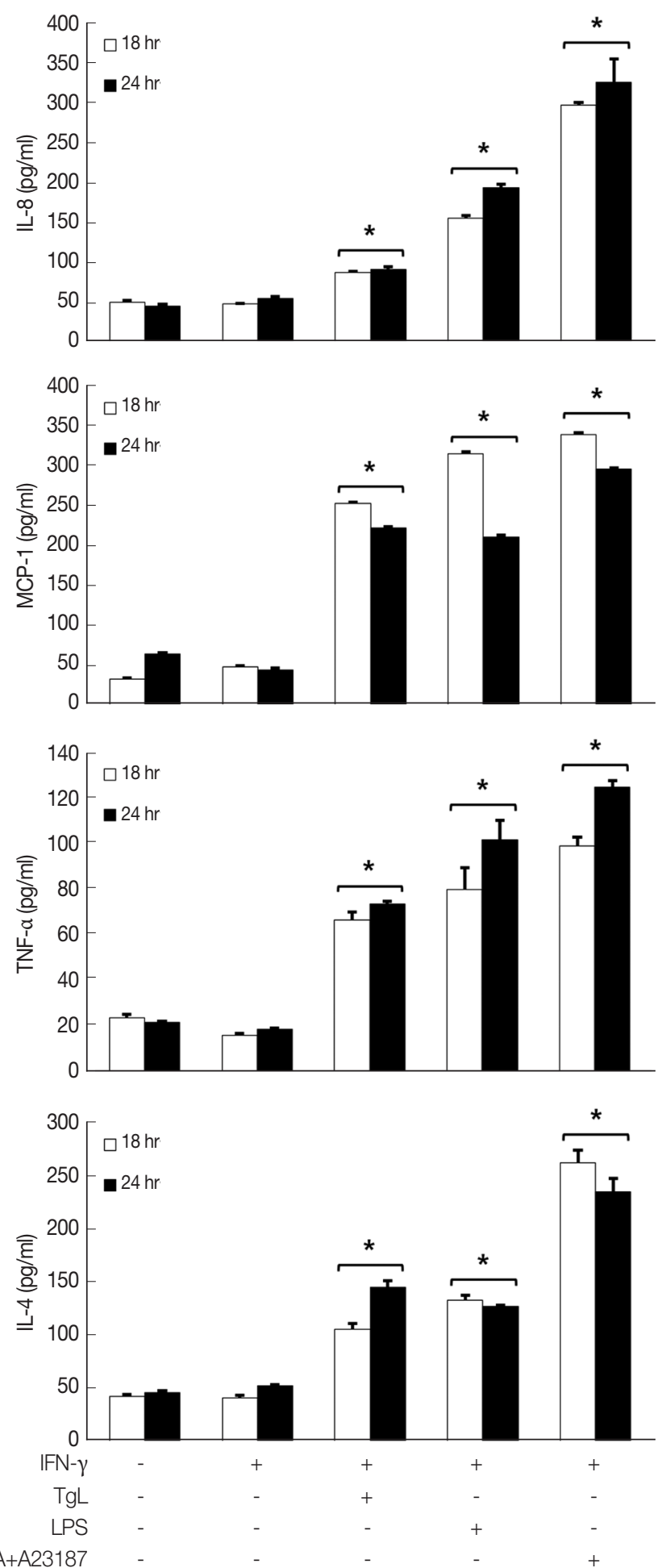

$\mathrm{PMA}+\mathrm{A} 23187$

Fig. 1. Increased production of IL-8, MCP-1, TNF-a and IL-4 mRNAs and proteins by HMC-1 cells incubated with T. gondii lysate. HMC-1 cells were pretreated with IFN- $\gamma$ for $1 \mathrm{hr}$ and then stimulated with T. gondii lysate or LPS. mRNA expression of each cytokine (A) and cytokine level (B) were increased. CXCR1 and CXCR2 was measured by western blotting with monoclonal antibodies to each receptor after $1 \mathrm{hr}$ of treatment with T. gondil lysate. PMA +A23187 was used as positive control. M, culture supernatant of HMC-1 alone; $\mathrm{M}^{*}$, culture supernatant of HMC-1 treated with IFN- $\gamma$; TgL, T. gondii lysate. ${ }^{*} P<0.05$ vs HMC-1 treated with IFN- $\gamma$. 
A

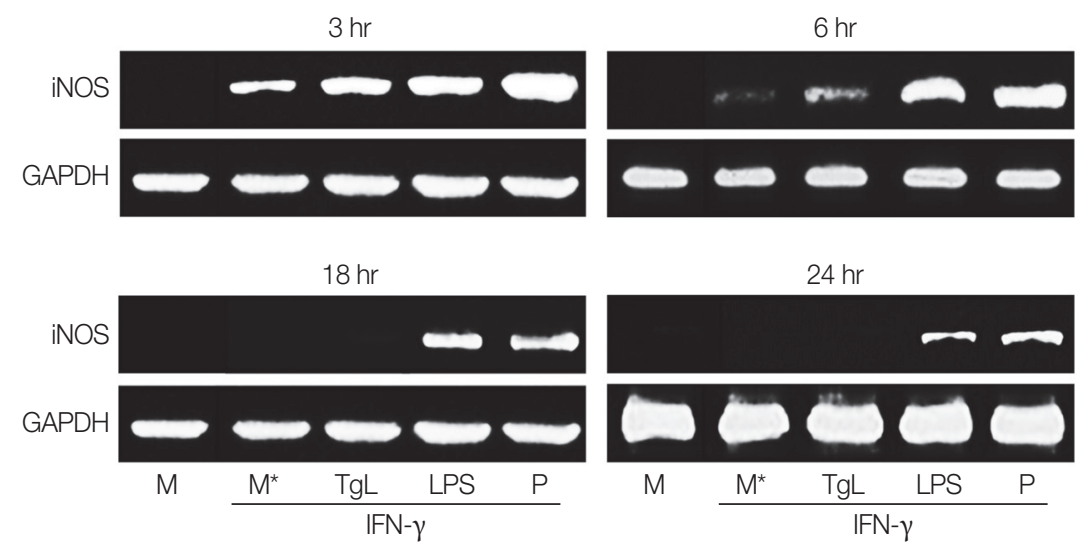

B

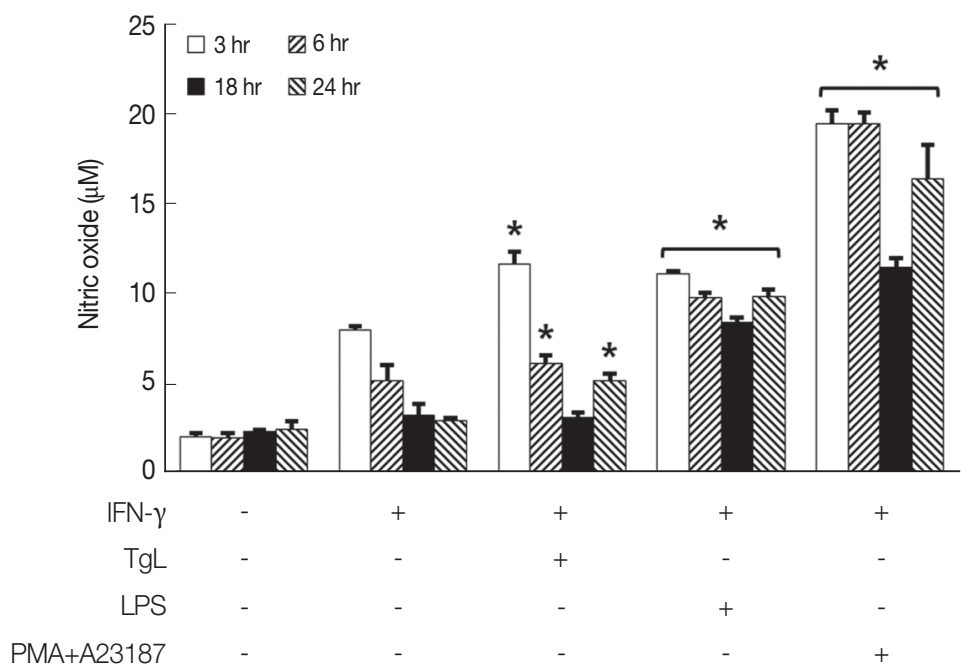

Fig. 2. iNOS mRNA and nitric oxide (NO) productions were up-regulated by HMC-1 cells stimulated with $T$. gondii lysate. HMC-1 cells were pretreated with IFN- $\gamma$ for $1 \mathrm{hr}$ and then stimulated with T. gondii lysate or LPS. iNOS mRNA (A) and NO production (B) were determined after $3 \mathrm{hr}, 6 \mathrm{hr}, 18 \mathrm{hr}$, and $24 \mathrm{hr}$ of incubation. NO production was measured with Griess reagent. PMA +A23187 was used as positive control. M, culture supernatant of HMC-1 cells alone; $\mathrm{M}^{*}$, culture supernatant of HMC-1 cells treated with IFN- $\gamma$; TgL, T. gondii lysate. ${ }^{*} P<0.05$ vs HMC- 1 cells treated with IFN- $\gamma$.

an important role in protective immune responses to oral infection by T. gondii [3]. Exposure to T. gondii causes mast cell to activate, degranulate and release mediators, proteases and cytokines [12]. Increases in mast cells numbers may be involved in the balance between inflammation and wound healing [13].

In the current study we found that IL- 8 and MCP-1 secretion was up-regulated after $18 \mathrm{hr}$ exposure to T. gondii lysate. This result is in agreement with our previous report that infection with $T$. gondii tachyzoites leads to increased secretion of IL-8 and MCP-1 by HeLa cells and fibroblasts [14]. Up-regulation of TNF- $\alpha$ and IL-4 mRNAs was observed in HMC-1 cells treated with T. gondii lysate for $18 \mathrm{hr}$ and $24 \mathrm{hr}$, respectively. Pro- duction of both cytokines increased in T. gondii lysate- or LPStreated HMC-1 cells indicating that $T$. gondii lysate induces inflammatory effect in the cells. T. gondii lysate alone did not increase cytokine production in HMC-1 cells. However, pretreatment of IFN- $\gamma$ resulted in increased cytokine production in the cells. Therefore, IFN- $\gamma$ was thought to be acted as a trigger for HMC-1 cells in cytokine production by T. gondii lysate.

The functions of chemokines induced by intracellular pathogens include leukocyte recruitment, cell mediated immunity and anti-protozoal activity. IL-8 induces a rapid and transient increase of $\mathrm{Ca}^{2+}$ in mast cells. HMC-1 cells express the CXCL8 chemokine receptors, CXCR1 and CXCR2 [15-18]. Increased levels of these receptors were observed on HMC-1 
cells stimulated with T. gondii lysate for $1 \mathrm{hr}$ (Fig. 1C).

The release of mediators by mast cell activation plays an important role in modulating inflammation during $T$. gondii infection $[6,16]$. In protozoal infections these mast cells are characterized by degranulation and the production of pro-inflammatory mediators, such as TNF- $\alpha$ [13]. The mast cell activator, compound 48/80, up-regulated Th1 cytokine mRNA (IFN- $\gamma$, IL-12p40, TNF- $\alpha$ ), and the mast cell stabilizer, disodium cromoglycate, increased Th2 cytokine mRNA (IL-4, IL-10) [12].

Mast cells are effector cells involved in clearance of parasites including Trichomonas vaginalis (T. vaginalis) [6]. We observed that rat peritoneal mast cells (RPMCs) were involved in the inflammatory response to $T$. vaginalis infection. Increased release of histamine and TNF- $\alpha$ were observed in RPMC-stimulated T. vaginalis ESP or live trichomonads [19]. Activation of mast cells has been reported to trigger production of cytokines and inflammatory mediators by protozoan parasites such as Plasmodium sp., Leishmania sp., and T. gondii [12].

Several protozoan parasites have evolved strategies to evade NO-mediated anti-microbicidal activity. Inducible nitric oxide synthase (iNOS)-derived NO can inhibit leucocyte adhesion in the micro-vasculature during ongoing inflammation. T. gondii infection partially inhibits NO production by murine macrophages and thus promotes parasite survival in phagocytic cells $[12,20,21]$. Leishimania sp. and Trypanosoma cruzi are known to inhibit iNOS expression $[22,23]$. We investigated HMC-1 cells were treated with T. gondii lysate to determine whether $T$. gondii infection affects NO production. Increased iNOS mRNA and NO production were observed at $3 \mathrm{hr}$ PI and it then declined by $6 \mathrm{hr}$.

Mast cells induce recruitment of other immune cells to initiate inflammation. In the present study, we observed that $T$. gondii lysate stimulated the production of chemokines (CXCL8, MCP-1), cytokines (TNF- $a$, IL-4) and NO production in HMC-1 cells. Therefore, activated mast cells by T. gondii lysate may be involved in innate and adaptive immune responses against $T$. gondii infection.

\section{CONFLICT OF INTEREST}

The authors declare no conflict of interest related to this study.

\section{REFERENCES}

1. Henderson WR Jr, Chi EY. The importance of leukotrienes in mast cells-mediated Toxoplasma gondii cytotoxicity. J Infect Dis 1998; 177: 1437-1443.

2. Długońska H. Toxoplsma gondii and mast cells. Ann Parasitol 2014; 60: 235-238.

3. Cruz A, Mendes ÉA, de Andrade MV, do Nascimento VC, Cartelle CT, Arantes RM, Melo JR, Gazzinelli RT, Ropert C. Mast cells are crucial in the resistance against Toxoplasma gondii oral infection. Eur J Immunol 2014; 44: 2949-2954.

4. Rodríguez NE, Wilson ME. Edsinophils and mast cells in leishmaniasis. Immunol Res 2014; 59: 129-141.

5. S Ferreira GL, Mineo JR, Oliveira JG, V Ferro EA, Souza MA, D Santos AA. Toxoplsma gondii and mast cell interactions in vivo and in vitro: experimental infection approaches in Calomys callosus (Rodentia, Cricetidae). Microbes Infect 2004; 6: 172-181.

6. Huang B, Huang S, Chen Y, Zheng H, Shen J, Lun ZR, Wang Y, Kasper LH, Lu F. Mast cells modulate acute Toxoplasmosis in murine models. PLoS One 2013; 8: 10; e77327.

7. Smith NL, Abi Abdallah DS, Butcher BA, Denkers EY, Baird B, Holowka D. Toxoplasma gondii inhibits mast cell degranulation by suppressing phospholipase $\mathrm{C} \gamma$-mediated $\mathrm{Ca}^{2+}$ mobilization. Front Microbiol 2013; 4: 179.

8. Park GC, Ryu JS, Min DY. The role of nitric oxide as an effector of macrophage-mediated cytotoxicity against Trichomonas vaginalis. Korean J Parasitol 1997; 35: 189-195.

9. Bierly AL, Shufesky WJ, Sukhumavasi W, Morelli AE, Denkers EY. Dendritic cells expressing plasmacytoid marker PDCA-1 are Trojan horse during Toxoplasma gondii infection. J Immunol 2008; 181: 8485-8491.

10. Lambert H, Barragen A. Modelling parasite dissemination: host cell subversion and immune evasion by Toxoplasma gondii. Cell Microbiol 2010; 12: 292-300.

11. Leng J, Butcher BA, Denkers EY. Dysregulation of macrophage signal transduction by Toxoplsma gondii: past progress and recent advances. Parasite Immunol 2009; 31: 717-728.

12. Lu F, Huang S. The roles of mast cells in parasitic protozoan infections. Front Immunol 2017; 8: 363.

13. Vukman KV, Lalor R, Aldridge A, O'Neill SM. Mast cells: new therapeutic target in helminth immune modulation. Parasite Immunol 2016; 38: 45-52.

14. Lee EJ, Heo YM, Choi JH, Song HO, Ryu JS, Ahn MH. Suppressed production of pro-inflammatory cytokines by LPS-activated macrophages after treatment with Toxoplasma gondii lysate. Korean J Parasitol 2008; 46: 145-151.

15. Inamura H, Kurosawa M, Okano A, Kayaba H, Majima M. Expression of the interleukin-8 receptors CXCR1 and CXCR2 on cord-blood-derived cultured human mast cells. Int Arch Allergy Immunol 2002; 128: 142-150.

16. Gaddi PJ, Yap GS. Cytokine regulation of immunopathology in toxoplasmosis. Immunol Cell Biol 2007; 85: 155-159. 
17. Denney CF, Eckmann L, Reed S. Chemokine secretion of human cells in response to Toxoplasma gondii infection. Infect Immun 1999; 67: 1547-1552.

18. Nilsson G, Mikovits JA, Metcalfe DD, Taub DD. Mast cell migratory response to interleukin- 8 is mediated through interaction with chemokine receptor CXCR2/interleukin-8RB. Blood 1999; 93: 2791-2797.

19. Im SJ, Ahn MH, Han IH, Song HO, Kim YS, Kim HM, Ryu JS. Histamine and TNF- $\alpha$ release by rat peritoneal mast cells stimulated with Trichomonas vaginalis. Parasite 2011; 18: 49-55.

20. Seabra SH, de Souza W, DaMatta RA. Toxoplasma gondii partially inhibits nitric oxide production of activated murine macrophages. Exp Parasitol 2002; 100: 62-70.
21. Lüder CG, Algner M, Lang C, Bleicher N, Gross U. Reduced expression of the inducible nitric oxide synthase after infection with Toxoplasma gondii facilitates parasite replication in activated murine macrophages. Int J Parasitol 2003; 33: 833-844.

22. Pakianathan DR, Kuhn RE. Trypanosoma cruzi affects nitric oxide production by murine peritoneal macrophages. J Parasitol 1994; 80: 432-437.

23. Proudfoot L, Nikolaev AV, Feng GJ, Wei WQ, Ferguson MA, Brimacombe JS, Liew FY. Regulation of the expression of nitric oxide synthase and leishmanicidal activity by glycoconjugates of Leishmania lipophosphoglycan in murine macrophages. Proc Natl Acad Sci USA 1996; 93: 10984-10989. 